\title{
Practice corner: setting EBM in motion
}

In addition to time pressures that we encounter when searching for evidence to support care decisions for individual patients, it may be difficult for clinicians to apply the evidence that we find. The rate limiting step may not be doing the search, but the steps needed in "setting evidence-based medicine (EBM) in motion."

We present an example of a search for evidence by a Physician Assistant (PA) student that highlights this challenge. PAs receive accelerated training in the medical model and work in teams under physician supervision. Approximately 40000 PAs currently work in the US in a wide range of settings and specialties. Practising EBM has become an important component of training for PAs.

During an internal medicine rotation, a PA student encountered a common clinical practice unsupported by current evidence-administration of nebulised albuterol in patients with community acquired pneumonia (CAP). While this practice may be justified in patients with underlying chronic obstructive pulmonary disease (COPD) who also present with CAP, this student questioned the grounds for its use in patients with CAP who do not have COPD.

\section{Clinical scenario}

A 68 year old man presented to the emergency department with fever, chills, and a non-productive cough of 1 week's duration. He had fatigue, headache, rhinorrhoea, and mild nausea, but denied dyspnoea. He had no history of smoking or COPD. He had atrial fibrillation and was taking warfarin for stroke prevention.

On admission, his temperature was $38.4{ }^{\circ} \mathrm{C}$, heart rate was 108 beats/minute, respiratory rate was 24 breaths/minute, blood pressure was $156 / 88 \mathrm{~mm} \mathrm{Hg}$, and oxygen saturation was $86 \%$ by pulse oximetry on room air. Rales were heard in both lung bases and in the right middle lobe. Chest radiography showed a diffuse infiltrate in the right middle and lower lobes. Complete blood count showed a white blood cell count of $22000 \mathrm{cells} / \mathrm{ml}$ with a left shift, and arterial blood gases showed mild respiratory acidosis.

One dose of ceftriaxone was administered parenterally, and a course of azithromycin was started. Albuterol, 5\% solution, delivered by nebuliser 3 times daily was also ordered, in addition to a combination of inhaled ipratropium and albuterol, delivered by metered dose inhaler every 4 hours as needed. During the hospital stay, his pneumonia resolved, but his heart rate increased to 150 beats/minute and his blood pressure rose from $156 / 88$ to $200 / 110 \mathrm{~mm} \mathrm{Hg}$.

\section{Clinical question}

Although there was no institutional protocol for use of nebulised albuterol for treatment of CAP, the house staff often ordered it. The PA student queried: In a 68 year old man with CAP and no underlying COPD, does use of nebulised $\beta 2$ agonists improve symptoms? What is the risk of harm in this patient?

\section{Search strategy}

Firstly, a treatment guideline was sought to clarify recommendations regarding use of nebulised albuterol for treatment of CAP. The American Thoracic Society guidelines for management of
$\mathrm{CAP}^{1}$ were rapidly retrieved through PubMed, UpToDate, and MD Consult. The British Thoracic Society (BTS) guidelines for the management of CAP in adults ${ }^{2}$ were also found in PubMed. Both sets of guidelines were relevant to our patient, but neither guideline discussed the use of nebulised albuterol in the treatment of CAP. The BTS guidelines had a section on general management, which discussed the use of adjunctive therapies for CAP, but nebulised albuterol was not mentioned. Evidence from controlled clinical trials was mentioned in the guideline for "bottle blowing,"3 but not for physiotherapy.

Having not fully answered our question with a review of relevant guidelines (and having not attracted the attention of anyone who could change the patient's treatment plan), we searched PubMed again, this time specifically for studies on the use of albuterol in patients with CAP. No relevant trials were found on the use of nebulisers for CAP.

To identify evidence about harm with the use of albuterol, PubMed was searched using the terms nebulised albuterol, cardiac arrhythmias, and randomised or controlled clinical trials. No trials were found. When just the content terms were searched, 9 articles, not directly relevant to our patient, were found. One prospective, open label study on the effect of nebulised albuterol (for treatment of asthma) on cardiac rhythm was found. ${ }^{4} 10$ patients were studied, and although no adverse effect on cardiac rhythm or blood pressure was found, the study did not convince the team that no potential for harm existed in this, or other patients, especially when there was no clear indication for use of albuterol.

Recognising that searching and appraising the literature are not the only important aspects of practicing EBM, we consulted an experienced pulmonologist, who practises and teaches using the EBM model. In addition to reviewing treatment plans for multiple cases of CAP requiring hospital admission with the Nurse Practitioner/Physician Assistant service, he recommended review of the Centre for Evidence-Based Medicine website at Mount Sinai Hospital in Toronto, Ontario, Canada (www.cebm.utoronto.ca/), which suggested bubble blowing as a method for helping clear secretions. ${ }^{2-3}$ This served as an excellent, rapid approach to finding good information on treatment of CAP, and confirmed the evidence previously found in the literature search.

\section{Application of the evidence to this, and future patients}

The treatment plan for this patient was not altered by the student's rapid search for evidence. Changes in usual care for a common illness required a comprehensive search and discussion among all clinicians in our institution caring for patients with CAP. The clinical team reviewed the results of the search and because no evidence was found to support use of albuterol in patients like ours, changes were made to future practice. As a result of this process, which took a few hours and evolved over several weeks, orders for bronchodilators for patients with CAP are now made on an individual basis, depending on the presence of patient comorbid illnesses, such as COPD. 


\section{Conclusion}

The need for a rapid search for evidence is sometimes, but not always, important to the care of an individual patient. In this case, the speed of the search did not affect the ability of the PA student to apply the evidence to the patient. Setting the evidence in motion may require communication of search results to other members of the clinical team and may affect the care of future patients. Although the catalyst for setting EBM in motion was a student, the evidence, including the results of further research, along with the judgment of the experienced pulmonologist, convinced the clinical team to make changes to usual care and to base future treatment of this common condition on the best available evidence.

\section{Acknowledgements}

We would like to thank Dermot Killian, MD, Mercy Pulmonary Associates, for his precepting and teaching of PA students through the University of New England, Portland, Maine, USA, and his help in preparing this manuscript. He served his residency in Respirology at St. Joseph's Hospital, Division of McMaster University.

Thanks also, to Bob McNellis, MPH, PA-C, of the American Academy of Physician Assistants, Alexandria, Virginia, USA, for his review of the manuscript.

MARK RAO, MS, PA-C Holy Family Hospital Methuen, Massachusetts, USA NOEL J GENOVA, MA, PA-C Mercy Primary Care Portland, Maine, USA

1 Niederman MS, Mandell LA, Anzueto A, et al. Guidelines for the management of adults with community-acquired pneumonia. Diagnosis, assessment of severity antimicrobial therapy, and prevention. Am J Respir Crit Care Med 2001;163:1730-54.

2 British Thoracic Society Standards of Care Committee. BTS Guidelines for the Management of Community Acquired Pneumonia in Adults. Tho rax 2001;56 Suppl 4:IV1-64.

3 Bjorkqvist M, Wiberg B, Bodin L, et al. Bottle-blowing in hospital-treated atients with community-acquired pneumonia. Scand J Infect Dis 1997;29:77-82.

4 Dickens GR, McCoy RA, West R, et al. Effect of nebulized albuterol on serum potassium and cardiac rhythm in patients with asthma or chronic obstructive pulmonary disease. Pharmacotherapy 1994;14:729-33.

\section{Evidence-based decision making-the six step approach}

The basic concept of evidence-based medicine proposes to make health related decisions based on a synthesis of internal and external evidence. Internal evidence is composed of knowledge acquired through formal education and training, general experience accumulated from daily practice, and specific experience gained from an individual clinician-patient relationship. External evidence is accessible information from research. It is the explicit use of valid external evidence (eg, randomised controlled trials) combined with the prevailing internal evidence that defines a clinical decision as "evidence-based." To realise this concept in day to day clinical practice, the EvidenceBased Medicine Working Group proposed a 5 step strategy, ${ }^{1}$ corresponding to step 1 and steps 3 to 6 shown in the left hand column of the table

In teaching this 5 step approach, we encountered several difficulties. We noticed a growing hesitance to accept this strategy as students advanced in their medical training. In the presence of well established methods of treatment or diagnosis, this resistance rises even more, regardless of the level of training. We assume that this barrier is associated with the process of socialisation into the health professions. Throughout medical education students are virtually "trained" to make decisions under the condition of uncertainty. Advanced students and to a greater extent clinicians lose some of their ability to differentiate between scientific evidence and what seems to be evident. If we intend to implement evidence-based medicine more efficiently, we need to modify the way students and clinicians learn to make decisions.

Therefore, an additional step was introduced in our evidencebased medicine teaching programme (step 2 in the table). Students were to provide answers to their clinical questions based on their current knowledge (internal evidence) before continuing with the remaining steps of the evidence-based process. ${ }^{2}$ Our collective experience concerning this additional step was extremely positive. The students using this new step were satisfied that their pre-existing knowledge had been integrated into the evidence-based approach. By explicitly documenting their internal evidence, students used the remaining steps of the process to evaluate not only the best evidence in making a clinical decision but also to assess the accuracy of their internal evidence, the grounds upon which their preconcep-

The 6 steps of evidence-based decision making

\begin{tabular}{|c|c|c|}
\hline Step & Action & Explanation \\
\hline 1 & Transformation of the clinical problem into 3 or 4 part question & $\begin{array}{l}\text { (a) relevant patient characteristics and problem(s), (b) leading intervention, } \\
\text { (c) alternative intervention, (d) clinical outcomes or goals. }\end{array}$ \\
\hline 2 & Additional step: answer to the question based on "internal evidence" only & $\begin{array}{l}\text { Internal evidence: acquired knowledge through professional training and } \\
\text { experience (in general and applied to the patient). Should be documented } \\
\text { before proceeding to step } 3 \text {. }\end{array}$ \\
\hline 3 & Finding "external evidence" to answer the question & $\begin{array}{l}\text { External evidence: obtained from textbooks, journals, databases, experts. } \\
\text { The value of the external evidence will be highly variable, see step } 4 .\end{array}$ \\
\hline 4 & Critical appraisal of the external evidence & $\begin{array}{l}\text { Should answer } 3 \text { questions: (1) Are the results valid? (2) Are the results } \\
\text { clinically important? (3) Do the results apply to my patient? (or is my } \\
\text { patient so different from those in the study that the results do not apply?) }\end{array}$ \\
\hline 5 & Integrating external and internal evidence & $\begin{array}{l}\text { The } 2 \text { sources of information (external and internal) may be supportive, } \\
\text { non-supportive, or conflicting. How the decision is made when } \\
\text { non-supportive or conflicting will depend on multiple factors. }\end{array}$ \\
\hline 6 & Evaluation of decision making process & $\begin{array}{l}\text { Once the decision has been made, the process and the outcome are } \\
\text { considered and opportunities for improvement are identified. }\end{array}$ \\
\hline
\end{tabular}


tions were based, and the usefulness of the available literature in supporting a decision for their patient.

The health authority of Alto Adige in northern Italy initiated and supported a project, the "Bressanone Model," in which the effects of implementing evidence-based medicine on the quality of health care were to be shown. In this model we used the six step approach, which proved to be successful in the student project to teach experienced clinicians. ${ }^{3}$ The participants were asked to name problems of their day to day practice that lacked either an effective or an efficient solution. The evidence-based medicine support group helped participants to phrase the 3 or 4 part questions. Subsequently, the physicians were asked to submit their individual answers to the questions before continuing with steps 3 to 6 .

Agreement between internal and external evidence varies. Completing the full process could result in finding evidence that confirms the internal evidence, validating and strengthening the clinician's or student's confidence in the decision. The process could also reveal that little evidence exists to support the decision or that the available evidence is equivocal. In such cases, other factors such as cost or inconvenience to the patient may need to be given greater consideration. Possibly, the best external evidence found is not in agreement with the internal evidence. This represents a particularly valuable experience for the clinician or student because it may avoid an ill advised decision. It also shows the fallibility of making decisions on uncertain ground based on internal evidence alone. This in turn will hopefully promote the routine assimilation of external evidence in clinical decision making. The documentation and comparison of steps 2 and 5 , used as a research tool or quality assurance outcome measure, could provide valid information on the effects of evidence-based medicine on clinical decision making.

In case of conflicting internal and external evidence, clinicians have several options. They may change their mind and align it with the external evidence. They may determine that the external evidence is not sufficiently convincing and remain with the original decision. Or, they may choose to discuss with the patient the conflict between the internal and external evidence in a manner that enables the patient to take part in the decision making process. This last approach is recommended because patient preference is considered an essential part of the evidence-based decision making process ${ }^{1}$ and decisions often need to be made in the absence of clear research findings.

$$
\begin{array}{r}
\text { FRANZ PORZSOLT, MD, PHD } \\
\text { University Hospital Ulm } \\
\text { Ulm, Germany } \\
\text { Ludwig Maximilians University } \\
\text { Munich, Germany } \\
\text { ANDREA OHLETZ, MD } \\
\text { ANKE THIM } \\
\text { Ludwig Maximilians University } \\
\text { Munich, Germany } \\
\text { DAVID GARDNER, MD } \\
\text { Dalhousie University } \\
\text { Halifax, Nova Scotia, Canada } \\
\text { HELMUTH RUATTI, MD } \\
\text { HORAND MEIER, MD } \\
\text { Bressanone Hospital } \\
\text { Bressanone, Alto Adige, Italy } \\
\text { NICOLE SCHLOTZ-GORTON } \\
\text { University Hospital Ulm } \\
\text { Ulm, Germany } \\
\text { LAURA SCHROTT, PHD }
\end{array}
$$

Bureau for Education of Health-Care Persomnel Autonomous Province of Bolzano, Alto Adige, Italy

1 Sackett DL, Straus SE, Richardson WS, et al. Evidence-based medicine: how to practice and teach EBM. Second edition. Toronto: Churchill Livingstone, 2000.

2 Porzsolt F, Sellentin C. Der sechste schritt in der anwendung der evidencebased medicine. Z Arztl Fortbild Qual Sich 2000;94:619-20.

3 Porzsolt F, Thim A, Ruatti $\mathrm{H}$, et al. Methode zur Implementierung des Health Technology Assessment an einem Lehrkrankenhaus. Bundesgesundheitsblatt - Gesundheitsforschung - Gesundheitsschutz 2001;44:908-14.

\section{Journals reviewed for this issue*}

$\begin{array}{ll}\text { Acta Obstet Gynecol Scand } & \text { Arch Pediatr Adolesc Med } \\ \text { Age Ageing } & \text { Arch Surg } \\ \text { Am J Cardiol } & \text { Arthritis Rheum } \\ \text { Am J Med } & \text { BJOG } \\ \text { Am J Obstet Gynecol } & \text { BMJ } \\ \text { Am J Psychiatry } & \text { BrJ Gen Pract } \\ \text { Am J Public Health } & \text { BrJ Psychiatry } \\ \text { Am J Respir Crit Care Med } & \text { BrJ Surg } \\ \text { Ann Emerg Med } & \text { CMAJ } \\ \text { Ann Intern Med } & \text { Chest } \\ \text { Ann Surg } & \text { Circulation } \\ \text { Arch Dis Child } & \text { Cochrane Library } \\ \text { Arch Gen Psychiatry } & \text { Crit Care Med } \\ \text { Arch Intern Med } & \text { Diabetes Care } \\ \text { Arch Neurol } & \text { Gastroenterology }\end{array}$

Gut

Heart

Hypertension

JAMA

J Am Coll Cardiol

J Am Coll Surg

J Am Geriatr Soc

J Clin Epidemiol

J Fam Pract

J Gen Intern Med

$\mathrm{J}$ Infect Dis

J Intern Med

J Neurol Neurosurg Psychiatry

J Pediatr

*Approximately 60 additional journals are reviewed. This list is available on request.

J Vasc Surg

Lancet

Med Care

N Engl J Med

Neurology

Obstet Gynecol

Pain

Pediatrics

Rheumatology

Spine

Stroke

Surgery

Thorax 